\title{
Knowledge, Attitudes and Practices of Patients Regarding Chronic Wound Care and Point Prevalance of Chronic Wounds at Surgical and Medical Units in Teaching Hospital Karapitiya, Sri Lanka
}

\author{
Priyadarshani R A C ${ }^{1}$, Samarawickrama M B ${ }^{2}$ \\ ${ }^{I}$ Nursing Degree Programme, ${ }^{2}$ Department of Anatomy, Faculty of Medicine, University of Ruhuna, Sri Lanka \\ Corresponding Author: Dr M B Samarawickrama (MBBS, MS) Senior Lecturer and Specialist in General \\ Surgery, Faculty of Medicine, University of Ruhuna, Sri Lanka. samaramb@gmail.com
}

\begin{abstract}
Introduction: Management of chronic wounds remains a challenging clinical problem. The correct and efficient management of wounds by health professionals as well as the compliance of patients are essential for healing of these wounds.

Objective: To identify the knowledge, attitudes and practices of patients regarding chronic wound care and to assess point prevalence of different types of chronic wounds in surgical and medical units in Teaching Hospital Karapitiya (THK), Sri Lanka.

Methodology: This study was performed on patients who were admitted and treated for chronic wounds at surgical and medical units, in THK during a one month period from $1^{\text {st }}$ April 2016 to $30^{\text {th }}$ April 2016. Their knowledge on aetiology, treatments, prevention and associated conditions of chronic wounds, attitudes on newer treatments, causes, effectiveness of non medical treatments and personal belief regarding chronic wounds and individual practices in treating chronic wounds were assessed using a pretested, interviewer administered questionnaire. Results were analyzed using the aggregate score calculated based on their answers (right or wrong) to those individual questions.

Results: The study sample comprised of 207 subjects that include 145 (70\%) males and 62 (30\%) females. The knowledge level was unsatisfactory in $83.6 \%$ (173) of the study sample. When considering attitudes, $64.7 \%$ (134) of participants had negative attitudes towards chronic wound care. In terms of practice, results showed that 56\% (116) of participants had unsatisfactory level of practice. Association between knowledge, attitude and practices with selected demographic variables was assessed by using Pearson chi square test. The point prevalence of wounds were diabetic wounds 38.2\%(79), bed sore 11.1\% (23), surgical site wound 10.6\%(22), burn 9.2\%(19), venous ulcers 7.7\%(16), arterial insufficiency ulcers 2.4\% (5) and other types 20.8\%(43). Conclusion: The results revealed that there were strong associations of knowledge, attitudes and practices with age and educational status. Therefore it is necessary to improve and develop educational strategies to create awareness of patients, for the effective prevention of occurrence of chronic wounds and prevention of recurrences of chronic wounds. Prevention of diabetes may cause to reduce the burden of chronic wounds by a considerable proportion.
\end{abstract}

Keywords: Chronic wounds, knowledge, attitude, practices

\section{Introduction}

A wound is defined as damage or disruption to the normal anatomical structure and function (Robson MC; et al. 2001). Wound healing remains a challenging clinical problem and correct and efficient management is essential for proper wound healing. Much effort has been focused on wound care with an emphasis on new therapeutic approaches and the development of technologies for acute and chronic wound management (Velnar $\mathrm{T}$; et al. 2009). Normal wound healing is a dynamic and complex process involving a series of coordinated events, including bleeding, coagulation and initiation of an acute inflammatory response to the initial injury. The inflammatory response leads to regeneration, migration and proliferation of connective tissue and parenchyma cells and synthesis of extracellular matrix proteins. Then it leads to remodeling of new parenchyma and connective tissue and collagen deposition. (Velnar T et al. 2009). Chronic wounds are those that fail to progress through this normal stages of healing and they cannot be repaired in an orderly and timely manner (Robson MC et al. 2001, Velnar T et al. 2009).

Presence of such wound is nuisance to the patient and burden to the society as it needs repeated wound dressing with or without admission to a hospital. This will increase health care cost of a country and reduces the earning capacity of individual which will have direct impact on economy of the country. Therefore it is 
important to evaluate the causes for chronic ulcers and patients' knowledge, attitude and practices regarding chronic wound which will help in managing these wounds and taking measures to prevent occurring of such wounds and this was the main aim of this study.

\section{Materials and methods}

A descriptive cross sectional study was conducted to obtain information on knowledge, attitudes and practices of patients regarding chronic wound care in surgical and medical units in Teaching Hospital Karapitiya (THK) and convenience sampling technique was used. THK is one of the largest government hospitals in Sri Lanka. The study sample comprised of 207 patients who were treated for chronic wounds in THK and met the inclusion criteria during the time period of data collection. As a data collecting tool pre tested interviewer administered questionnaire was used which included socio - demographic data, chronic wound relevant data and details regarding patient's attitudes, knowledge and practices affecting chronic wounds. The wound relevant data included questions regarding the location, nature, duration, pain level of wound and associated factors and diseases. There were questions which assess patient's knowledge, attitudes and practices separately and IBM SPSS version 20 was used as data analysis tool. Pearson's chi square test was used to assess the association between categorical variables. Statistical significance was set at $\mathrm{p}<0.05$. Ethical clearance was obtained from the ethical committee of the Faculty of Medicine, University of Ruhuna.

\section{Demographic data}

\section{Results}

The study sample comprised 207 patients with 70\% (145) of male and 30\% (62) of female. Their age ranged from 15 years to 95 years with the mean of 53.4 years and most of them $\{21.3 \%$ (44) $\}$ were between $55-64$ age groups.

\begin{tabular}{lrr}
\hline Age ranges & Frequency & Percent \\
\hline 15 - 24 years & 8 & 3.9 \\
25 - 34 years & 16 & 7.7 \\
35 - 44 years & 39 & 18.8 \\
$45-54$ years & 41 & 19.8 \\
55 - 64 years & 44 & 21.3 \\
65 - 74 years & 24 & 11.6 \\
75 years $<$ & 35 & 16.9 \\
\hline Total & 207 & 100.0 \\
\hline
\end{tabular}

Table 1 frequency and percentages of participants according to their age ranges

The level of education was poor in majority of the participants as $95(45.9 \%)$ had education up to or below grade five and only $7.7 \%$ (16) had higher education. (Table 2)

\begin{tabular}{lrr}
\hline & Frequency & Percent \\
\hline never gone to the school & 26 & 12.6 \\
Up to grade 5 & 69 & 33.3 \\
Up to GCE O/L & 60 & 29.0 \\
Up to GCE A/L & 36 & 17.4 \\
higher education & 16 & 7.7 \\
\hline Total & 207 & 100.0 \\
\hline
\end{tabular}

Table 2; frequency and percentages of participants according to their educational state

The cause of the wound of these patients varied. According to the cause the frequency and percentages of wounds are given in the table 3 . The most common type was diabetic wound $\{38.2 \%(79)\}$.

\begin{tabular}{lrr}
\hline Type & Frequency & Percent \\
\hline diabetic wound & 79 & 38.2 \\
bed sore & 23 & 11.1 \\
venous ulcer & 16 & 7.7 \\
arterial ulcer & 5 & 2.4 \\
surgical site wound & 22 & 10.6 \\
Burn & 19 & 9.2 \\
other(trauma) & 43 & 20.8 \\
\hline Total & 207 & 100.0 \\
\hline
\end{tabular}

Table3; frequency and percentages of wounds according to type of wound 
Most common location of wound was foot $68.6 \%$ (142). Other sites were back and buttock $15.9 \%(33)$, chest and abdomen 6.8\%(14), hands 3.9\%(8) head and neck 2.9\%(6) and other 1.9\%(4). (Table 4)

\begin{tabular}{lrr}
\hline Site & Frequency & Percent \\
\hline head/neck & 6 & 2.9 \\
chest/abdomen & 14 & 6.8 \\
back/buttock & 33 & 15.9 \\
Foot & 142 & 68.6 \\
Hands & 8 & 3.9 \\
Other & 4 & 1.9 \\
\hline Total & 207 & 100.0 \\
\hline
\end{tabular}

Table 4; frequency and percentages of wounds according to location of wound

Even though these patients had chronic wounds most of them $\{63.8 \%$ (132) $\}$ started treatment within 2 weeks of onset of the wound. However $9.2 \%$ (19) of patients delayed their treatment for more than one year. (Table 5)

\begin{tabular}{lrr}
\hline Duration of delay for $1^{\text {st }}$ treatment & Frequency & Percent \\
\hline$<1$ weeks & 1 & .5 \\
$<2$ weeks & 131 & 63.3 \\
2 week-1 month & 24 & 11.6 \\
$1-3$ month & 15 & 7.2 \\
$3-6$ month & 4 & 1.9 \\
6-9 month & 9 & 4.3 \\
$9-12$ month & 4 & 1.9 \\
1year< & 19 & 9.2 \\
Total & 207 & 100.0 \\
\hline
\end{tabular}

Table 5; frequency and percentages of delay for seeking $1^{\text {st }}$ consultation for wounds treatment

When considering any interventional treatment, $68.1 \%$ (141) of patients had undergone wound toilets while $21.7 \%$ (45) were subjected to amputation and $20.3 \%$ (42) were treated with skin grafting. Some of the patients had undergone more than one types of interventions $\{21(10.1 \%)\}$

\section{Knowledge on chronic wound care}

There were 24 questions to assess the knowledge regarding chronic wound care. One point was given to each correct answer. The total score one could achieve was 24 . The score that achieved by the participants were ranged from 12-23 out of 24. The mean score was 18 while the SD was 2.3. Then the knowledge of the patients was categorized into three levels according to the number of points that one scored. Those who obtained mean minus SD $\{(18-2.3)$ score $<15.7\}$ were considered as having poor knowledge level while the Mean plus SD $(18+2.3)$ \{score> 20.3 $\}$ were considered as good knowledge level. The score from 15.8 to 20.2 was considered as average knowledge level. Accordingly the most of the patients had average knowledge regarding the care for chronic wounds. (Table 6)

\begin{tabular}{lrr}
\hline Knowledge level & Frequency & Percent \\
\hline Poor & 29 & $14 \%$ \\
Average & 144 & $69.6 \%$ \\
Good & 34 & $16.4 \%$ \\
\hline Total & 207 & $100 \%$ \\
\hline
\end{tabular}

Table 6 knowledge distribution according to categorized levels

For the purpose of further analysis these three levels of knowledge were categorized as satisfactory knowledge when the score was 20.3 or more and unsatisfactory knowledge when the score was less than 20.3. According to this categorization, 83.6\% (173) of patients had unsatisfactory knowledge level and $16.4 \%$ (34) of patients had satisfactory knowledge level regarding chronic wound care.

\section{Attitudes on chronic wound care}

There were 13 statements to assess participants' attitudes. Five options (strongly disagree, disagree, no idea, agree and strongly agree) were given for each statement for participants to respond and 11 statements were considered for giving marks. A scoring method was applied as to give the best mark (4) for the best option for that particular attitude and 0 for the poor attitude. Accordingly the maximum score that one could achieve was 44. Therefore the score one could achieve was ranged from 0-44. The higher score indicated the positive attitudes. According to the findings the minimum score that one achieved was 16 and the maximum was 44 . The mean score was 25.8. Therefore those who obtained score of less than 25.8 were considered as having negative attitudes and those who obtained more than 25.8 were considered having positive attitudes. (Table 7) 
Knowledge, Attitudes and Practices of Patients Regarding Chronic Wound Care and Point ..

\begin{tabular}{lrr}
\hline Attitude & Frequency & Percent \\
\hline Negative attitudes & 134 & $64.7 \%$ \\
Positive attitudes & 73 & $35.3 \%$ \\
\hline Total & 207 & 100.0 \\
\hline
\end{tabular}

Table 7 Attitudes distribution according to score categorization

\section{Practices on chronic wound care}

There were 25 questions to assess practices. One mark was given for the correct response so the maximum score that one could achieve was 25 . According to the score that one achieved, the level of practice was divided in to two categories satisfactory level and unsatisfactory level. The score obtained by participants ranged from 12-24 while the mean score was 17.7. Therefore those who obtained a score of less than 17.7 were considered as having unsatisfactory practices while those who achieved above this score was considered having satisfactory level of practices. (Table 8)

\begin{tabular}{lrr}
\hline Level of Practices & Frequency & Percent \\
\hline Unsatisfactory & $56 \%$ \\
Satisfactory & 116 & 91 \\
\hline Total & $44 \%$ \\
\hline
\end{tabular}

Table 8;Frequencies and percentages of level of practices

Relationship between knowledge and age

To assess relationship between knowledge and age, patients were divided into two groups as those above the age of 45 years and those below the age of 45 years.

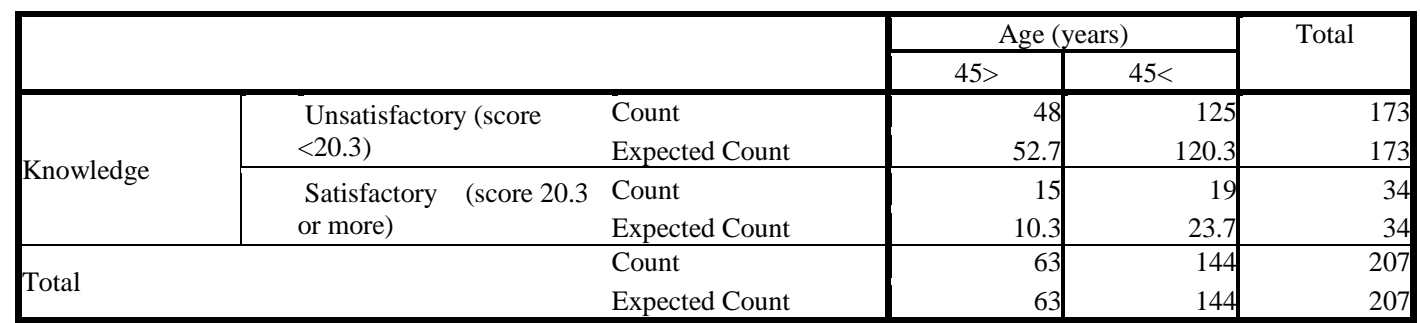

Table 9. Cross tab results of age with knowledge

Pearson chi value at the level 0.05 of significance was 3.597 and calculated table value was 0.05 . Calculated table value (0.05) was more than Pearson chi value (3.597). The results show that there was a positive correlation between knowledge and age regarding chronic wound care therefore there was a significant relationship between knowledge and age of patients regarding their chronic wound care

Relationship between knowledge and educational status

\begin{tabular}{|c|c|c|c|c|c|c|}
\hline & \multicolumn{3}{|c|}{ Educational status } & \multirow[t]{2}{*}{ Total } \\
\hline & & & Up to $\mathrm{O} / \mathrm{L}$ & Up to $A / L$ & Higher education & \\
\hline \multirow{4}{*}{ Knowledge } & \multirow{2}{*}{$\begin{array}{l}\text { Unsatisfactory (score } \\
<20.3 \text { ) }\end{array}$} & Count & 137 & 29 & 7 & 173 \\
\hline & & Expected Count & 129.5 & 30.1 & 13.4 & 173 \\
\hline & \multirow{2}{*}{$\begin{array}{l}\text { Satisfactory (score } \\
20.3 \text { or more) }\end{array}$} & Count & 18 & 7 & 9 & 34 \\
\hline & & Expected Count & 25.5 & 5.9 & 2.6 & 34 \\
\hline \multirow{2}{*}{ Total } & & Count & 155 & 36 & 16 & 207 \\
\hline & & Expected Count & 155 & 36 & 16 & 207 \\
\hline
\end{tabular}

Table 10; Cross tab results of educational status with knowledge

Pearson chi value at the level 0.05 of significance was 21.340 and calculated table value was 0.000 . Calculated table value $(0.000)$ was less than Pearson chi value (21.340). The results show that there was a significant positive correlation between knowledge and educational status regarding chronic wound care therefore there was significant relationship between knowledge and educational status of patients regarding their chronic wound care 
Knowledge, Attitudes and Practices of Patients Regarding Chronic Wound Care and Point ..

Relationship between attitudes and age

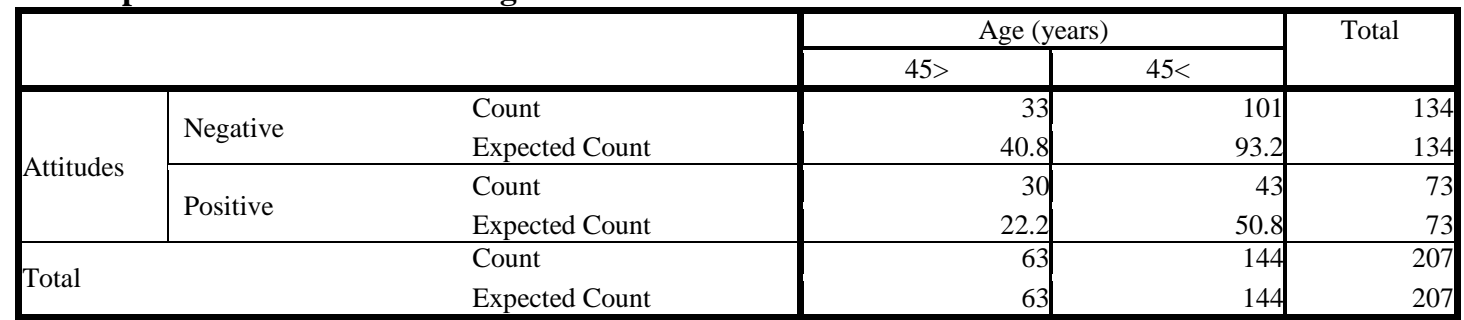

Table11; Cross tab results of attitudes with age groups

Pearson chi value at the level 0.05 of significance was 6.054 and calculated table value was 0.01 . Calculated table value (0.01) was less than Pearson chi value (6.054). The results show that there was a significant positive correlation between attitudes and the age regarding chronic wound care. Therefore there was significant relationship between attitudes and age groups of patients regarding their chronic wound care

Relationship between attitudes and educational status

\begin{tabular}{|c|c|c|c|c|c|c|}
\hline & \multicolumn{3}{|c|}{ Educational status } & \multirow[t]{2}{*}{ Total } \\
\hline & & & Up to $\mathrm{O} / \mathrm{L}$ & $\mathrm{Up}$ to $\mathrm{A} / \mathrm{L}$ & Higher education & \\
\hline \multirow{2}{*}{ Attitudes } & Negative & $\begin{array}{l}\text { Count } \\
\text { Expected Count }\end{array}$ & $\begin{array}{r}110 \\
100.3 \\
\end{array}$ & $\begin{array}{r}20 \\
23.3 \\
\end{array}$ & $\begin{array}{r}4 \\
10.4 \\
\end{array}$ & $\begin{array}{l}134 \\
134 \\
\end{array}$ \\
\hline & Positive & Count & 45 & 16 & 12 & 73 \\
\hline \multirow{2}{*}{ Total } & & $\begin{array}{l}\text { Expected Count } \\
\text { Count }\end{array}$ & $\begin{array}{r}54.7 \\
155\end{array}$ & $\begin{array}{r}12.7 \\
36\end{array}$ & $\begin{array}{c}5.6 \\
16\end{array}$ & $\frac{73}{207}$ \\
\hline & & Expected Count & 155 & 36 & 16 & 20 \\
\hline
\end{tabular}

Table 12; Cross tab results of attitudes with educational status

Pearson chi value at the level 0.05 of significance was 15.032 and calculated table value was 0.001 . Calculated table value (0.001) was less than Pearson chi value (15.032). The results show that there was a significant positive correlation between attitudes and educational status regarding chronic wound care therefore there was significant relationship between attitudes and educational states of patients regarding their chronic wound care

\section{Relationship between practices and age}

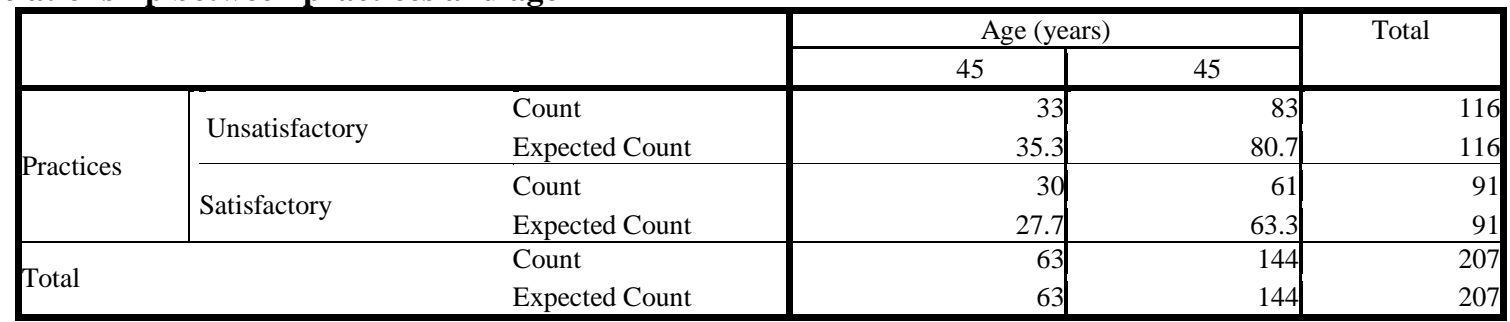

Table 13; Cross tab results of practices with age groups

Pearson chi value at the level 0.05 of significance was 0.492 and calculated table value was 0.483 . Calculated table value $(0.483)$ was less than Pearson chi value $(0.492)$. The results show that there was a relatively significant positive correlation between practices and age groups regarding chronic wound care. Therefore there was a significant relationship between practices and age groups of patients regarding their chronic wound care.

\section{Relationship between practices and educational status}

\begin{tabular}{|c|c|c|c|c|c|c|}
\hline & \multicolumn{3}{|c|}{ Educational states } & \multirow[t]{2}{*}{ Total } \\
\hline & & & Up to $\mathrm{O} / \mathrm{L}$ & Up to $\mathrm{A} / \mathrm{L}$ & Higher education & \\
\hline \multirow{3}{*}{ Practices } & Unsatisfactory & $\begin{array}{l}\text { Count } \\
\text { Expected Count }\end{array}$ & $\begin{array}{r}105 \\
86.9 \\
\end{array}$ & $\begin{array}{r}11 \\
20.2 \\
\end{array}$ & $\begin{array}{r}0 \\
9.0 \\
\end{array}$ & $\begin{array}{l}116 \\
116\end{array}$ \\
\hline & \multirow{2}{*}{ Satisfactory } & Count & 50 & 25 & 16 & 9 \\
\hline & & $\begin{array}{l}\text { Expected Count } \\
\text { Count }\end{array}$ & $\begin{array}{r}68.1 \\
155\end{array}$ & $\begin{array}{r}15.8 \\
36\end{array}$ & 7.0 & 20 \\
\hline Total & & Expected Count & 155 & 36 & 16 & \\
\hline
\end{tabular}

Table 14; Cross tab results of practices with level of education 
Pearson chi value at the level 0.05 of significance was 38.503 and calculated table value was 0.000 . Calculated table value (0.000) was less than Pearson chi value (38.503). The results show that there was a significant positive correlation between practices and level of educational status regarding chronic wound care. Therefore there was a significant relationship between practices and level of educational status of patients regarding their chronic wound care.

Relationship between knowledge and attitudes

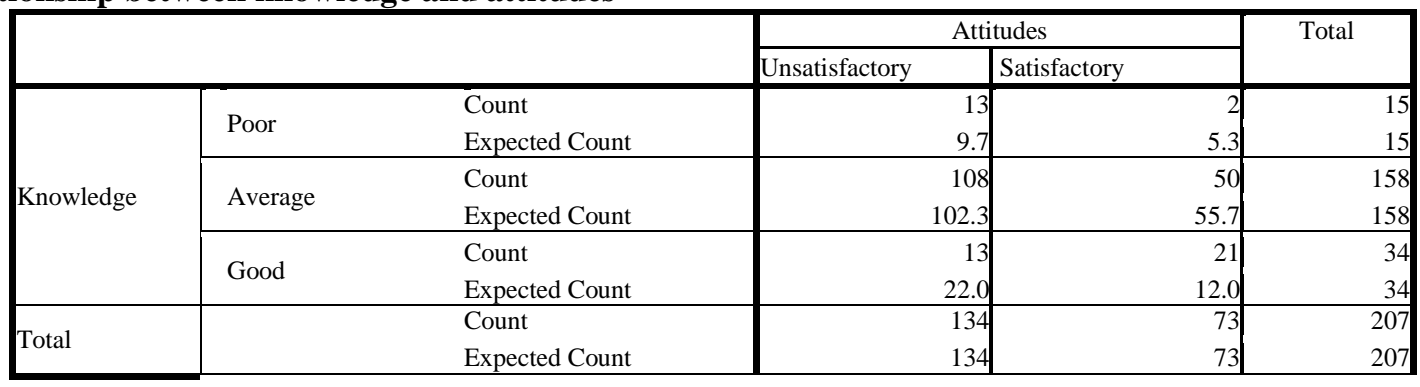

Table 15; Cross tab results for knowledge and attitudes

Correlation analysis was conducted to determine the relationship between knowledge and attitudes variable and their sub dimensions using Pearson correlation and coefficient. Pearson chi value at the level 0.05 of significance was 14.526 and calculated table value was 0.000 . The results show that there was a significant positive correlation between knowledge and attitudes regarding chronic wound care therefore there was significant relationship between knowledge and attitudes of patients regarding their chronic wound care

\section{Relationship between knowledge and practices}

\begin{tabular}{|c|c|c|c|c|c|}
\hline & & & \multicolumn{2}{|c|}{ Practices } & \multirow[t]{2}{*}{ Total } \\
\hline \multirow{4}{*}{ Knowledge } & & & Unsatisfactory & Satisfactory & \\
\hline & Poor & $\begin{array}{l}\text { Count } \\
\text { Expected Count }\end{array}$ & $\begin{array}{l}10 \\
8.4\end{array}$ & $\begin{array}{l}5 \\
6.6\end{array}$ & $\begin{array}{l}15 \\
15\end{array}$ \\
\hline & Average & $\begin{array}{l}\text { Count } \\
\text { Expected Count }\end{array}$ & $\begin{array}{l}93 \\
88.5\end{array}$ & $\begin{array}{l}65 \\
69.5\end{array}$ & $\begin{array}{l}158 \\
158\end{array}$ \\
\hline & Good & $\begin{array}{l}\text { Count } \\
\text { Expected Count }\end{array}$ & $\begin{array}{l}13 \\
19.1\end{array}$ & $\begin{array}{l}21 \\
14.9\end{array}$ & $\begin{array}{l}34 \\
34\end{array}$ \\
\hline \multicolumn{2}{|l|}{ Total } & $\begin{array}{l}\text { Count } \\
\text { Expected Count }\end{array}$ & $\begin{array}{l}116 \\
116\end{array}$ & $\begin{array}{l}91 \\
91\end{array}$ & $\begin{array}{l}207 \\
207\end{array}$ \\
\hline
\end{tabular}

Table 16; Cross tab results for knowledge and practices

Correlation analysis was conducted to determine the relationship between knowledge and practices variable and their sub dimensions using Pearson correlation and coefficient. Pearson chi value at the level 0.05 of significance was 5.573 and calculated table value was 0.062 . The results show that there was no significant positive correlation between knowledge and practices regarding chronic wound care. Therefore there was no significant relationship between knowledge and practices of patients regarding their chronic wound care

\section{Point prevalence of chronic wounds}

According to the findings of the study the most common type of ulcer $\{38.16 \%$ (79) $\}$ was the diabetic wounds. Others included pressure ulcers $\{11.1 \%(22)\}$, surgical site wounds $\{10.6 \%(23)\}$, burns $\{9.2 \%(19)\}$, venous ulcers $\{7.7 \%(16)\}$, arterial insufficiency ulcers $\{2.4 \%(5)\}$ and the rest included traumatic and other ulcers $\{20.8 \%(43)\}$. Therefore the commonest type of chronic wound was diabetic wounds. 


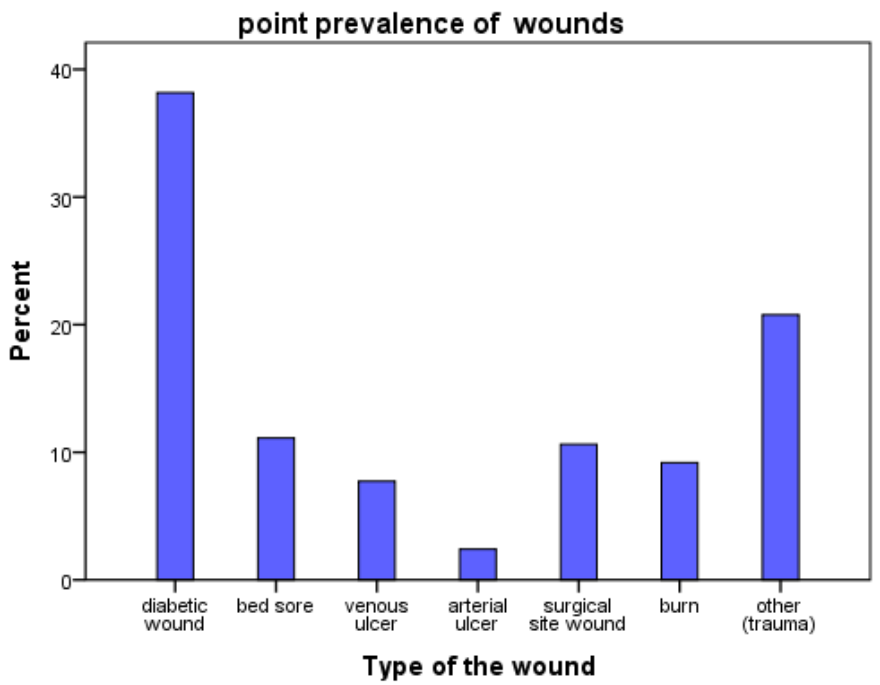

Figure 1. Point prevalence chronic wounds of patients' regarding chronic wound care

\section{Introduction}

\section{Discussion}

Chronic wounds are very common throughout the world. It is evident that chronic wounds account for a significant proportion of population morbidity and hospital admissions. Despite the considerable progress in the management of wounds that has been made over recent years, wound healing remains a challenge for many clinicians regardless of professional discipline or experience (Flanagan, M. 2004). Therefore it is necessary to have a good knowledge, positive attitudes and safe practices about chronic wound care among patients for a better outcome and incensement of quality of life. For our best knowledge there were no such researches found in the literature that has been done to assessed knowledge, attitude and practices of patients' regarding chronic wounds care. But there are few studies on knowledge and attitude of healthcare professionals regarding wound care (Ian D et al. 2003. Nurhusien Nuru et al. 2015). The main objective of the study was to assess the knowledge, attitudes and practices about chronic wound care among patients with non-healing chronic wounds in surgical and medical units in Teaching Hospital Karapitiya, Galle, Sri Lanka.

Chronic wounds may result from various causes which include neuropathic, pressure, arterial and venous insufficiency, burns and vasculities. (Robert Nunan et al. (2014), Kumarasinghe S P W et al. (2004). Numerous pathophysiological and metabolic factors can affect wound healing and result in poor outcome (Velnar T et al. 2009). Similarly inadequate care of an ulcer can have an immediate serious medical outcome or a great socio-economic impact. For example, as an immediate result, a diabetic patient may lose a limb through an emergency amputation or even die of septicaemia or ketoacidosis if a wound is not managed properly (Kumarasinghe SPW. 2004).

\section{Demography}

Out of 207 patients $70 \%$ (145) were male and 30\% (62) were female in this study. However a study done in Iorland showed the proportion of the women were twice more likely to be affected than men (Shubhangi Vinayak Agale. 2013). The prevalence of these chronic wounds increases with age. For example, it has been estimated that chronic wounds affect $0.6-3 \%$ of those age over 60 years and increasing up to $5 \%$ over the age of 80years. (Shubhangi Vinayak Agale. 2013) In our study sample patients' age ranges from 15 to 95 years and the mean age range were 55 to 64 which were falling with the world figures.

Wounds were classified according to the cause. The most common type of wounds was diabetic wound [38.2\%(79)] and the others included, bed sore [11.1\%(23)], surgical site wound [10.6\%(22)], burn [9.2\%(19)], venous ulcers [7.7\%(16)], arterial insufficiency ulcers [2.4\% (5)] and other type of wounds [20.8\%(43)]. But different population statistics shows varying types of prevalence. According to the review done by (Shubhangi Vinayak Agale. 2013) the most common type in US, Germany and Ireland were venous ulcers while diabetic ulcers took $3^{\text {rd }}$ place in western countries. In Sri Lanka the common causes of chronic ulcers include, diabetic ulcers, neuropathic ulcers, pressure ulcers, burns, venous ulcers and arterial ulcers (Kumarasinghe SPW et al. 2004). The location of the wound was in the foot in majority of the patients [68.6\% (142)]. The other sites included back and buttock [15.9\%(33)], chest and abdomen [6.8\%(14)], hands [3.9\%(8)] head and neck $[2.9 \%(6)]$ and other $[1.9 \%(4)]$. Therefore the most common site of chronic wound is lower limbs and this is the most common site in other countries as well. (Shubhangi Vinayak Agale. 2013). The most of these patients were 
Knowledge, Attitudes and Practices of Patients Regarding Chronic Wound Care and Point ..

treated with wound toilet and dressing [68.1\%( 141)]. The other interventions were amputations [21.7\%( 45)] and skin grafting [20.3\%(42)].

\section{Knowledge, Attitude and Practice}

For the better outcome of a treatment for any conditions patient's compliance are important. Coyer et al. (2005) highlighted this fact and said when patients have poor knowledge concerning their underlying condition, their treatment options, and their own role in treatment will directly impact on the compliance for the treatment. Therefore it is very important to assessed patients knowledge regarding chronic wound care so that we can take steps to improve their knowledge if it is lacking. According to the findings of our study the majority had an average knowledge [69.6\% (144)]. However only $16.4 \%(34)$ had satisfactory knowledge regarding chronic wound care. Flanagan, M. (2004) explain the importance of new knowledge of health professionals regarding the wound epidemiology, etiology and pathology for better wound management. One should not forget the knowledge of the patients' is also equally important when implementing such new techniques as patients' compliance matters during treatment.

Many factors like education level might have contributed to the low level of knowledge regarding chronic wound care among patients in this study as there was a significant association with the knowledge and patients' educational level. Most of the patients had lower level of education. There were $74.9 \%$ (155) of patients educated up to $\mathrm{O} / \mathrm{L}, 17.4 \%$ (36) of patients educated up to $\mathrm{A} / \mathrm{L}$ and only few patients $7.7 \%$ (16) had completed higher education.

Results revealed that majority of participants $\{64.7 \%(134)\}$ were in negative attitude level while $35.3 \%$ (73) were in positive attitudes level regarding chronic wound care. This mean they do not willing to change their mind to get rational treatment for their wounds. They have their own belief and remedy for these wounds. This results in non-healing chronic wounds. We could not find similar studies to compare our results as studies done on this topic are spars.

When considering the results regarding their practices majority of participants $\{56 \%(116)\}$ had unsatisfactory level of practices while 44\% (91) had satisfactory level of practices. Even though most of the participants $\{95.7 \%(198)\}$ agreed to secure their wounds contamination from domestic flies which help to improve wound healing which is a good practice. On the other hand $68.1 \%$ (141) of the participants had done various types of hand medicines to their wound before seeking proper treatments. This and the other malpractices had lead to the chronic nature of wounds in addition to its causative factor. Participants' knowledge, attitudes and practices were compared with age groups and level of educations. The results revealed that there were strong associations between each knowledge, attitudes and practices variable with selected demographic variable. Age groups were divided in to two groups as less than 45 years and more than 45 years. Educational levels were divided into three groups as educated up to $\mathrm{O} / \mathrm{L}$, up to $\mathrm{A} / \mathrm{L}$ and completed higher education. With regards to the relationship of knowledge and age groups and educational levels, results show that there was a significant association between the variables. When assessed the relationship of attitudes with age groups and educational levels, the results revealed that there was a significant association between these variables. Similarly there was a significant positive correlation of practices with age groups and education levels regarding chronic wound care. Therefore, there also was a significant relationship between practices and age and educational levels of patients regarding their chronic wound care. When considering these results, all the variables were interrelated with patient's age and the educational level. Correct knowledge, attitude and practice are important for the patients' compliance for the treatments. Reasons for wounds to become chronic directly related to its cause and indirectly related to improper treatment. Patients' knowledge, attitude and practices have influence on getting proper treatments even though it is freely available in our country. Therefore to prevent occurrence of chronic wound needs to improve all these three aspects of the patients.

\section{Point prevalence}

According to the results of the study, out of 207 patients' point prevalence of wounds were diabetic wounds $38.2 \%(79)$, bed sore $11.1 \%$ (23), surgical site wound 10.6\%(22), burn 9.2\%(19), venous ulcers $7.7 \%(16)$, arterial insufficiency ulcers $2.4 \%$ (5) and other type of wounds were $20.8 \%(43)$.

According to Bouter KP et al. (1993) and El-Nahas MR et al. (2008) twelve studies conducted in eight countries reported prevalence of diabetic ulcer varied from $1.2 \%$ to $20.4 \%$ in the hospital setting. In our study point prevalence of diabetic wound was $38.2 \%$. Therefore in our hospital setting diabetic ulcer prevalence almost doubled the maximum figure of those studies. However the pressure ulcer prevalence in our study was $11.1 \%$ (23). In Scandinavia, the prevalence of open pressure ulcers varies between $13 \%$ and $27 \%$ (Bermark S et al. 2004. Wann-Hansson $C$ et al. 2008). This shows that even though the figures for diabetic wounds are higher than certain world figures and prevalence of the pressure ulcer is lower than available figures. 


\section{Conclusion}

Chronic wounds remain a main health problem worldwide. Types of chronic wounds according to the causes include diabetic wounds, bed sore, surgical site wound, burn, venous ulcers, arterial insufficiency ulcers and traumatic wounds. The commonest type of wounds in this study was diabetic ulcers while in western countries venous ulcer has become the most common type. Patients' knowledge, good attitude and practices are important in implementing newer management technique. In the study sample patients' knowledge, attitude and practices were not up to the standard. There was a significant correlation of these three factors with each other. Similarly the results revealed that there were strong associations of knowledge, attitudes and practices with age and educational status. Therefore it is necessary to improve and develop educational strategies to create awareness of patients, for the effective prevention of occurrence of chronic wounds and prevention of recurrences of chronic wounds. Prevention of diabetes may cause to reduce the burden of chronic wounds by a considerable proportion.

\section{References}

[1]. Martin C robson, David L Steed, Michael G Franz Wound healing: biologic features and approaches to maximize healing trajectorie current problem in surgery February 2001vol. 38 issue 2, p A1, 72-140. at http://www.currprobsurg.com/article/S00113840(01)00036-3/pdf

[2]. Velnar T, Bailey T, Smrkolj V. (2009) the wound healing process: an overview of the cellular \& molecular mechanisms. The Journal of International Medical Research. 37:1528-1542.

[3]. Ian D. Graham, Margaret B. Harrison,Mona Shafey, David Keast, Knowledge and attitudesregarding care of leg ulcers Survey of family physicians Canadian Family Physician, VOL 49: JULY. 2003 p 896-902

[4]. Nurhusien Nuru, Fisseha Zewdu, Senafikish Amsalu and Yohannes Mehretie Knowledge and practice of nurses towards prevention of pressure ulcer and associated factors in Gondar University Hospital, Northwest Ethiopia, BMC Nursing (2015) 14:34

[5]. Robert Nunan, Keith G. Harding, Paul Martin Clinical challenges of chronic wounds: searching for an optimal animal model to recapitulate their complexity Disease Models \& Mechanisms 2014 7: 1205-1213; doi: 10.1242/dmm.016782 at https://www.ncbi.nlm.nih.gov/pmc/articles/PMC4213725/

[6]. Kumarasinghe SPW. Wound care in Sri Lanka: our patients deserve better care. Ceylon Medical Journal 2004; 49: 4-5

[7]. Shubhangi Vinayak Agale Chronic leg ulcer: Epidemiology,Aetiopathogenesis and management Ulcers Volume 2013 (2013), Article ID 413604, 9 pages at https://www.hindawi.com/journals/ulcers/2013/413604/\#B10

[8]. Coyer, Fiona M., Edwards, Helen E., \& Finlayson, Kathleen J. (2005) National Institute for Clinical Studies Report for Phase 1, Evidence Uptake Network : Best Practice Community Care for Clients with Chronic Venous Leg Ulcers. Queensland University of Technology, Brisbane, QLD.

[9]. Flanagan, M. (2004). Barriers to the implementation of best practice in wound care. WoundsUK,74-84 at http://www.woundsinternational.com/media/issues/123/files/content_87.pdf

[10]. Bouter KP et al. The diabetic foot in Dutch hospitals: epidemiological features and clinical outcome. Eur J Med 1993; 2(4):215218 .

[11]. El-Nahas MR et al. The prevalence of risk factors for foot ulceration in Egyptian diabetic patients. Practical Diabetes International 2008; 25(9):362-366.

[12]. Wann-Hansson C, Hagell P, Willman A. Risk factors and prevention among patients with hospital-acquired and pre-existing pressure ulcers in an acute care hospital. Journal of Clinical Nursing.2008;17:1718-27. [PubMed]

[13]. Bermark S, Zimmerdahl V, Muller K. Prevalence investigation of pressure ulcers. EWMA Journal.2004;4:7-11. 